OPEN ACCESS

Edited by:

Zhen Cheng,

Stanford University, United States

Reviewed by:

Mike MingQiang Zheng, Yale University School of Medicine,

United States

Lina $W u$,

Harbin Medical University, China

${ }^{*}$ Correspondence:

Nathaniel M. Alpert alper@@et.mgh.harvard.edu

${ }^{\dagger}$ These authors share first authorship

Specialty section: This article was submitted to Medical Physics and Imaging, a section of the journal

Frontiers in Physiology

Received: 10 January 2020 Accepted: 21 April 2020

Published: 15 May 2020

Citation:

Alpert NM, Pelletier-Galarneau M,

Kim SJW, Petibon Y, Sun T, Ramos-Torres KM, Normandin MD and El Fakhri G (2020) In-vivo Imaging of Mitochondrial Depolarization of Myocardium With Positron Emission Tomography and a Proton Gradient Uncoupler.

Front. Physiol. 11:491. doi: 10.3389/fphys.2020.00491

\section{In-vivo Imaging of Mitochondrial Depolarization of Myocardium With Positron Emission Tomography and a Proton Gradient Uncoupler}

\author{
Nathaniel M. Alpert ${ }^{1 * t}$, Matthieu Pelletier-Galarneau ${ }^{1,2+}$, Sally Ji Who Kim ${ }^{1}$, \\ Yoann Petibon ${ }^{1}$, Tao Sun ${ }^{1}$, Karla M. Ramos-Torres ${ }^{1}$, Marc D. Normandin ${ }^{1}$ and \\ Georges El Fakhri ${ }^{1}$
}

' Gordon Center for Medical Imaging, Department of Radiology, Massachusetts General Hospital, Harvard Medical School, Boston, MA, United States, ${ }^{2}$ Department of Medical Imaging, Montreal Heart Institute, Montreal, QC, Canada

Background: We recently reported a method using positron emission tomography (PET) and the tracer ${ }^{18} \mathrm{~F}$-labeled tetraphenylphosphonium $\left({ }^{18} \mathrm{~F}-\mathrm{TPP}{ }^{+}\right)$for mapping the tissue (i.e., cellular plus mitochondrial) membrane potential $\left(\Delta \Psi_{T}\right)$ in the myocardium. The purpose of this work is to provide additional experimental evidence that our methods can be used to observe transient changes in the volume of distribution for ${ }^{18} \mathrm{~F}_{-} \mathrm{TPP}^{+}$and mitochondrial membrane potential $\left(\Delta \Psi_{\mathrm{m}}\right)$.

Methods: We tested these hypotheses by measuring decreases of ${ }^{18} \mathrm{~F}^{\mathrm{TPP}} \mathrm{TP}^{+}$ concentration elicited when a proton gradient uncoupler, BAM15, is administered by intracoronary infusion during PET scanning. BAM15 is the first proton gradient uncoupler shown to affect the mitochondrial membrane without affecting the cellular membrane potential. Preliminary dose response experiments were conducted in two pigs to determine the concentration of BAM15 infusate necessary to perturb the ${ }^{18} \mathrm{~F}-\mathrm{TPP}^{+}$ concentration. More definitive experiments were performed in two additional pigs, in which we administered an intravenous bolus plus infusion of ${ }^{18} \mathrm{~F}-\mathrm{TPP}+$ to reach secular equilibrium followed by an intracoronary infusion of BAM15.

Results: Intracoronary BAM15 infusion led to a clear decrease in ${ }^{18} \mathrm{~F}^{-T P P}{ }^{+}$ concentration, falling to a lower level, and then recovering. A second BAM15 infusion reduced the ${ }^{18} \mathrm{~F}-\mathrm{TPP}^{+}$level in a similar fashion. We observed a maximum depolarization of $10 \mathrm{mV}$ as a result of the BAM15 infusion.

Summary: This work provides evidence that the total membrane potential measured with ${ }^{18} \mathrm{~F}^{-T P P}{ }^{+}$PET is sensitive to temporal changes in mitochondrial membrane potential.

Keywords: mitochondrial membrane potential, tissue membrane potential, tetraphenylphosphonium, positron emission tomography, BAM15 


\section{INTRODUCTION}

The mitochondrial membrane potential $\Delta \Psi_{\mathrm{m}}$ represents the energy stored in the electric field of the mitochondrion that is used to convert ADP to ATP. Importantly, mitochondrial membrane potential is normally regulated within rather narrow bounds (Kadenbach et al., 2011). Whenever the mitochondrial membrane potential is abnormally high or low, additional reactive oxygen species (ROS) are generated, leading to an environment toxic to mitochondria (Cui et al., 2012; Suski et al., 2018). Mitochondrial dysfunction has been shown to play a critical role in several pathologies, including heart failure (Kadenbach et al., 2011), ventricular arrhythmia (Aon et al., 2003; O'rourke et al., 2005; Rutledge and Dudley, 2013), myopathy (Widlansky et al., 2010; Walters et al., 2012; Pfeffer and Chinnery, 2013), diabetes (Green et al., 2004; Widlansky et al., 2010; De Felice and Ferreira, 2014), and cancer proliferation (Momcilovic et al., 2019). As mitochondrial membrane potential is an essential determinant of mitochondrial functional status (Chen, 1988; Duchen, 2004; O'rourke, 2016), its noninvasive quantitative mapping might provide a new biomarker in those mitochondrial-related diseases. Furthermore, as new mitochondrial therapies are developed (Fulda et al., 2010), noninvasive mapping of membrane potential may play a role in evaluation of response to therapy.

There is a long history of research on the measurement of $\Delta \Psi_{\mathrm{m}}$ dating back more than 50 years. Until about 10 years ago, work on $\Delta \Psi_{\mathrm{m}}$ was limited to bench-top experiments on cells (Rottenberg, 1979; Rottenberg, 1984), isolated mitochondria (Rottenberg, 1984; Wan et al., 1993), and isolated rat hearts (Kauppinen, 1983; Wan et al., 1993). This basic experimental approach often used a highly lipophilic cation, tetraphenylphosphonium labeled with tritium $\left({ }^{3} \mathrm{H}-\mathrm{TPP}^{+}\right)$, which readily diffuses into cells and mitochondria (Kamo et al., 1979). When applied to isolated rat hearts, the ${ }^{3} \mathrm{H}-\mathrm{TPP}^{+}$methodology is the forerunner to modern positron emission tomography (PET) scanning with lipophilic cations (Wan et al., 1993).

Due to the cellular and mitochondrial membrane potentials, the equilibrium concentration of $\mathrm{TPP}^{+}$in cytosol is 3 to 10 times higher than in the extracellular space (ECS), and 100 to 500 times higher in the mitochondria compared to the ECS (Murphy, 2008). Measurements of the mitochondrial membrane potential have typically relied on compartment models of the $\mathrm{TPP}^{+}$concentration, with the Nernst equation relating the concentrations on either side of a membrane to its electric potential (Nernst, 1889). A body of work has established ${ }^{3} \mathrm{H}$ $\mathrm{TPP}^{+}$as the primary reference tracer method for measuring $\Delta \Psi_{\mathrm{m}}$. However, the use of ${ }^{3} \mathrm{H}$-tracers is not appropriate for human investigation because of its ionizing radiation, long physical half-life and attendant radiotoxicity. Moreover, for in vivo studies in man or animals, the lack of externally detectable radiation means that tissues must be biopsied and processed in order to use the ${ }^{3} \mathrm{H}-\mathrm{TPP}^{+}$methodology.

To relax these limitations, we recently reported a method for quantitative in vivo PET mapping of the total (i.e., cellular plus mitochondrial) tissue membrane potential $\Delta \Psi_{\mathrm{T}}$, a proxy for $\Delta \Psi_{\mathrm{m}}$ (Alpert et al., 2018). We showed that our method, which relies on the measurement of the distribution volume of ${ }^{18}{\mathrm{~F}-\mathrm{TPP}^{+}}^{+}$using PET, provides measurements in normal and chronically injured pig myocardium that were consistent with prior work using ${ }^{3} \mathrm{H}-\mathrm{TPP}^{+}$. To extend the validation of the method, we now provide experimental evidence that (1) the distribution volume of ${ }^{18} \mathrm{~F}^{-\mathrm{TPP}^{+}}$is sensitive to changes in $\Delta \Psi_{\mathrm{m}}$ and (2) that it is possible to observe mitochondrial depolarization during the period of the PET measurement. To facilitate this study, we used a specific type of intravenous input function (bolus plus constant infusion) designed to achieve a secular equilibrium of ${ }^{18} \mathrm{~F}-\mathrm{TPP}^{+}$during which we measure the concentration of ${ }^{18} \mathrm{~F}^{-T P P}{ }^{+}$with PET. Then we perturbed the equilibrium with intracoronary infusion of a proton gradient uncoupler (Jastroch et al., 2014), BAM15 (Kenwood et al., 2014; To et al., 2019), that affects $\Delta \Psi_{\mathrm{m}}$ but not the cellular membrane potential.

The specific objectives of this study are to show: (1) coronary infusion of BAM15 causes the concentration of ${ }^{18} \mathrm{~F}^{-} \mathrm{TPP}^{+}$to decrease over time in the corresponding vascular territory, and (2) to determine the BAM15 dose at which changes in PET concentration can be observed.

\section{MATERIALS AND METHODS}

\section{Theory}

The volume of tracer distribution, $\mathrm{V}_{\mathrm{T}}$, is measurable with PET (Perrier and Mayersohn, 1982). Assuming a compartmental tissue model for a PET voxel (Perrier and Mayersohn, 1982; Alpert et al., 2018), and the volume of distribution can be written as

$$
\begin{gathered}
V_{T}=\frac{\bar{C}_{P E T}}{\bar{C}_{p}}=\left(1-f_{\text {ecs }}\right) \\
\left(f_{\text {mito }} \cdot e^{-\beta \Delta \Psi_{T}}+\left(1-f_{\text {mito }}\right) \cdot e^{-\beta \Delta \Psi_{c}}\right)+f_{e c s}
\end{gathered}
$$

where the experimental endpoints are $\overline{C_{\mathrm{PET}}}$, the steady-state tissue concentration of ${ }^{18} \mathrm{~F}-\mathrm{TPP}^{+}$measured by PET, $\overline{C_{\mathrm{p}}}$, the steady-state plasma concentration, $f_{\text {ecs }}$, the tissue volume fraction occupied by the ECS, and $f_{\text {mito }}$ the tissue volume fraction occupied by mitochondria. $\beta=\frac{z F}{R T}$ is a ratio of known physical constants $-F$ is Faraday's constant, $z$ denotes the valence, $R$ denotes the universal gas constant, and $T$ symbolizes the temperature in degrees Kelvin. $f_{\text {ecs }}$ is measured using ECGtriggered CT scans before and after administration of iodinated contrast media (see below). $f_{\text {mito }}$ was set to $0.2568 \mathrm{~mL} / \mathrm{mL}$ (Barth et al., 1992). See Alpert et al. (2018) for more details. There are several ways to measure $\mathrm{V}_{\mathrm{T}}$. One way is to use a bolus injection of ${ }^{18} \mathrm{~F}_{\text {-TPP }}{ }^{+}$and a dynamic PET acquisition protocol, followed by kinetic analysis of the measured activity concentration data (Alpert et al., 2018). Administering the tracer with intravenous bolus injection followed immediately by prolonged constant infusion allows an alternative approach requiring establishment of a secular equilibrium during which $\mathrm{V}_{\mathrm{T}}$ can be measured as a simple tissue-to-plasma concentration ratio (Endres and Carson, 1998; Carson, 2000). 


\section{Animal Welfare}

Animals used in this study were housed and maintained under the supervision of the Massachusetts General Hospital (MGH), Institutional Animal Care and Use Committee (IACUC), and our study was conducted under a protocol approved by the MGH IACUC.

\section{Animal Preparation}

Adult Yucatan minipigs were anesthetized with intramuscular telazol $(4.4 \mathrm{mg} / \mathrm{kg})$ and xylazine $(2 \mathrm{mg} / \mathrm{kg})$, tracheally intubated, and mechanically ventilated. Anesthesia was maintained with a mixture of isoflurane (1.5\%) and oxygen. Once intubated and under general anesthesia, swine were positioned supine on the procedure table with a heating pad underneath. All procedures were performed using aseptic technique. Bilateral auricular dorsolateral veins were cannulated with a $22 \mathrm{G}$ angiocatheter for administration of IV fluids and medications. Heparin (150 units $/ \mathrm{kg})$ was administered intravenously prior to introducer sheath placement and additional heparin administered as needed to maintain activated clotting time $(\mathrm{ACT})>200 \mathrm{~s}$. The femoral veins were cannulated percutaneously with $8 \mathrm{~F}$ introducer sheaths for administration of TPP, CT, contrast, and venous blood sampling. The left femoral artery was cannulated percutaneously with a $6 \mathrm{~F}$ introducer to monitor arterial blood pressure and blood gasses. A 7F introducer sheath was placed in the right femoral artery for introduction of a guide catheter. The $7 \mathrm{~F}$ guide catheter was inserted through the introducer and advanced into the ostium of the main left coronary artery under fluoroscopic guidance. Angiographic images of the coronary artery were obtained from the standard 25 degree left anterior oblique view with a 10 degree cranial angle. Intracoronary BAM15 drug delivery was accomplished with a $0.92 \mathrm{~mm}$ over the wire Maverick Angioplastic PTCA catheter (Boston Scientific). The drug delivery catheter was advanced over a $0.36 \mathrm{~mm}$ guide wire through the $7 \mathrm{~F}$ guide catheter. Under fluoroscopy, radio-opaque marker bands located at the tip of the catheter were used to position the catheter tip in the mid-left anterior descending (LAD) artery. Once drug delivery catheter position was confirmed by fluoroscopy, the $0.36 \mathrm{~mm}$ guide wire was withdrawn and the lumen used for intracoronary BAM15 delivery. Both catheters were anchored and fixed externally with sutures to avoid displacement during imaging.

Vascular access for cardiac hemodynamic monitoring was achieved via a $2 \mathrm{~cm}$ midline neck incision over the right side of the trachea. The right common carotid artery was identified and an $8 \mathrm{~F}$ introducer sheath inserted via a guide wire into the lumen of the artery. Two surgical ties were positioned on either side of the introducer sheath for bleeding control. Under fluoroscopic observation, the 5F Transonic Scisense catheter was inserted through the 8FR introducer, advanced across the aortic valve via the aortic root, and placed into the left ventricular chamber.

\section{PET/CT Scanning}

An intravenous bolus injection of $\sim 16 \mathrm{mCi}$ of ${ }^{18} \mathrm{~F}-\mathrm{TPP}^{+}$followed immediately with an infusion of ${ }^{18} \mathrm{~F}-\mathrm{TPP}^{+}(\sim 6 \mathrm{mCi}$ in $60 \mathrm{~mL}$, $0.33 \mathrm{~mL} / \mathrm{min}$ over $180 \mathrm{~min}$ ) were used for tracer administration.
PET list mode data were acquired for $150 \mathrm{~min}$ beginning $30 \mathrm{~min}$ after the start of ${ }^{18} \mathrm{~F}$-TPP ${ }^{+}$bolus/infusion using a hybrid PET/CT system (GE Discovery MI; Pan et al., 2019). List mode data were framed as a dynamic series of 2 min image volumes. PET data were reconstructed using an OSEM algorithm with CTbased attenuation correction to yield radioactivity concentration maps in units of $\mathrm{Bq} / \mathrm{cc}$ with 89 slices and a voxel size of $2.73 \mathrm{~mm} \times 2.73 \mathrm{~mm} \times 2.8 \mathrm{~mm}$. Reconstructed PET image volumes were reoriented into the standard short axis projection, segmented as standard 17 segment polar maps according to the ACNC guidelines (Dilsizian et al., 2016), and used to form time activity curves (TACs). These TACs were analyzed during the secular equilibrium and inspected for evidence of depolarization during infusion of BAM15.

\section{Blood Sampling}

Venous blood samples were drawn from the femoral vein in pigs 3 and 4 to estimate the ${ }^{18} \mathrm{~F}_{-} \mathrm{TPP}^{+}$concentration during secular equilibrium. Beginning at $90 \mathrm{~min}$ after tracer administration and ending $30 \mathrm{~min}$ later, samples were drawn every $6 \mathrm{~min}$.

\section{Measurement of Extracellular Space}

Myocardial $f_{\text {ECS }}$ was measured with a contrast-enhanced cardiac CT protocol consisting of three steps: First, a CT scan was performed to obtain baseline blood and myocardial attenuation in Hounsfield units (HU); second, a bolus of iodine contrast agent was administered intravenously ( $1.8 \mathrm{mgI} / \mathrm{kg} ; 3 \mathrm{~mL} / \mathrm{sec})$ using a power injector followed by a saline flush; third, a repeat CT scan was performed to measure blood and myocardial HU after a standard 15-min delay, required for the contrast agent to reach equilibrium between myocardium and blood pools (Treibel et al., 2015; Lee et al., 2016). All cardiac CTs were acquired with prospective ECG gating ( $\sim 65-75 \%$ of $\mathrm{R}-\mathrm{R}$ interval) and the following parameters: helical mode, tube voltage: $120 \mathrm{kVp}$; tube current: $200 \mathrm{mAs}$; gantry rotation time: $330 \mathrm{msec}$, matrix size: $512 \times 512$, voxel size: $0.70 \mathrm{~mm} \times 0.70 \mathrm{~mm} \times 5 \mathrm{~mm}$, and 100 slices. Non-local means filtering was applied to the reconstructed images to increase the image signal to noise ratio (Buades et al., 2005). The filtering parameters were: local patch size $3 \times 3 \times 3$, search window $5 \times 5 \times 3$. Next, the CT images were registered to the PET image (summation of late frames) to account for potential position mismatch between the $\mathrm{CT}$ and PET acquisitions. The pre- and post-contrast CT images were first rigidly aligned to the PET image, followed by elastic registration of the myocardium to refine alignment. The resulting deformation field was applied to both pre- and post-contrast CT images. All rigid and non-rigid registrations were performed using the open source software elastix (Klein et al., 2009).

Iodine contrast induces more absorption and scattering of $\mathrm{x}$-ray, which results in increases in CT attenuation. In heart, intravascular contrast rapidly permeates the ECS. The ECS fraction was calculated as $f_{\mathrm{ECS}}=\frac{\Delta H U_{\mathrm{M}}}{\Delta H U_{\mathrm{B}}} \times(1-H c t)$ where $\triangle H U_{\mathrm{M}}$ and $\triangle H U_{\mathrm{B}}$ represent the change in attenuation before and after contrast in the myocardium and in the blood, respectively, $\left(\Delta H U=\Delta H U_{\text {post-contrast }}-\Delta H U_{\text {pre-contrast }}\right)$, and Hct represents the hematocrit. 


\section{Intracoronary Dose Response of BAM15}

BAM15 was prepared with 3\% DMSO in 10\% P80. BAM15 dose response with respect to PET imaging was assessed in two minipigs: Beginning 50 min post injection/infusion of ${ }^{18} \mathrm{~F}-\mathrm{TPP}^{+}$, BAM15 was infused into the LAD coronary artery and the dose was increased in three levels. PET data were reconstructed as 75 frames of $2 \mathrm{~min}$ each, reoriented into the standard short axis projection, segmented as standard 17 segment polar maps, and used to form TACs. These TACs were inspected for evidence of depolarization. Visualization of distinct local minima in the TACs following BAM15 infusion was considered evidence of depolarization. The first dose-response experiment began with very conservative BAM15 dose while the second study used higher BAM15 doses to demonstrate that an effect could be observed. Bam15 dosing is summarized in Table 1. Global values of myocardial ${ }^{18} \mathrm{~F}^{-\mathrm{TPP}}{ }^{+}$concentrations were used as the endpoint for assessing if changes could be attributed to BAM15. Blood sampling was not performed in the dose-response studies.

TABLE 1 | Summary of BAM15 infusion dose and measurable effects on ${ }^{18} \mathrm{~F}^{-\mathrm{TPP}}{ }^{+}$concentration.

\begin{tabular}{|c|c|c|c|}
\hline & $\begin{array}{l}\text { Infusion BAM15 } \\
\text { concentration } \\
\text { (mg/min) }\end{array}$ & $\begin{array}{c}\text { Total BAM15 } \\
\text { infusion dose } \\
(\mathrm{mg})\end{array}$ & $\begin{array}{l}\text { Measurable } \\
\text { effects on } \\
{ }^{18} \mathrm{~F}-\mathrm{TPP}^{+} \\
\text {concentration }\end{array}$ \\
\hline \multirow[t]{3}{*}{ Dosing study \#1 } & 0.01 & 0.15 & None \\
\hline & 0.1 & 1.5 & None \\
\hline & 0.5 & 7.5 & $\begin{array}{l}\text { Delayed, mild } \\
\text { reversible decrease }\end{array}$ \\
\hline \multirow[t]{2}{*}{ Dosing study \#2 } & 1.0 & 25 & $\begin{array}{l}\text { Rapid, significant } \\
\text { reversible decrease }\end{array}$ \\
\hline & 1.2 & 12 & $\begin{array}{l}\text { Rapid decrease } \\
\text { and severe cardiac } \\
\text { dysfunction }\end{array}$ \\
\hline Study \#3 & 1.0 & 25 & $\begin{array}{l}\text { Rapid, significant } \\
\text { reversible decrease }\end{array}$ \\
\hline Study \#4 & 1.0 & 25 & $\begin{array}{l}\text { Rapid, significant } \\
\text { reversible decrease }\end{array}$ \\
\hline
\end{tabular}

\section{Volume of Distribution and Membrane Potential}

In pigs 3 and 4 , the distribution of ${ }^{18} \mathrm{~F}^{-\mathrm{TPP}^{+}}$was allowed to evolve for 100 min under constant infusion, leading to a secular equilibrium of ${ }^{18} \mathrm{~F}_{-} \mathrm{TPP}^{+}$in the myocardium. No BAM15 was administered during this period. Data obtained in the epoch 95100 min was used to measure $V_{\mathrm{T}}=\frac{\overline{C_{\mathrm{T}}}}{\overline{C_{\mathrm{p}}}}$ and to estimate $\Delta \Psi_{\mathrm{T}}$. Infusion of BAM15 commenced at $100 \mathrm{~min}$ and continued until $125 \mathrm{~min}$. In those cardiac segments showing a clear decrease in $\mathrm{TPP}^{+}$concentration, we used $V_{\mathrm{T}} \approx f_{\mathrm{m}} \cdot\left(1-f_{\mathrm{ECS}}\right) e^{-\beta \Delta \Psi_{\mathrm{T}}}$ as an approximation of Eq. 1 to estimate the value of $V_{T}$ and $\Delta \Psi_{T}$ in the period of lowest excursion, as well as for computation of parametric maps of $\Delta \Psi_{\mathrm{T}}$.

\section{RESULTS}

\section{Dosing Studies}

As shown in Figure 1A, during constant intravenous infusion of ${ }^{18} \mathrm{~F}_{-} \mathrm{TPP}^{+}$, the myocardial ${ }^{18} \mathrm{~F}^{-} \mathrm{TPP}^{+}$concentration rose nearly linearly between 40 and $95 \mathrm{~min}$ while the BAM15 infusion rate was increased ten-fold, from $0.01 \mathrm{mg} / \mathrm{min}$ (total $0.15 \mathrm{mg}$ ) to $0.1 \mathrm{mg} / \mathrm{min}$ (total $1.5 \mathrm{mg}$ ), with no measurable effects of BAM15. At $95 \mathrm{~min}$ the BAM15 dose was increased to $0.5 \mathrm{mg} / \mathrm{min}$ (total $7.5 \mathrm{mg}$ ) and the PET concentration decreased about $20 \mathrm{~min}$ after the beginning of BAM15 infusion.

Figure 1B shows the average myocardial TAC of the second dosing study. The BAM15 infusion rate was set at $1 \mathrm{mg} / \mathrm{min}$ and infused into the LAD artery over a $25 \mathrm{~min}$ period beginning at $100 \mathrm{~min}$ after the PET infusion began. The global ${ }^{18} \mathrm{~F}_{-} \mathrm{TPP}^{+}$myocardial concentration immediately decreased and a new secular equilibrium was observed in the period 110-120 min. At the end of the first BAM15 infusion the concentration of ${ }^{18} \mathrm{~F}^{-\mathrm{TPP}^{+}}$resumed a roughly linear increase until 155 min when the second BAM15 infusion started. The second infusion of $1.2 \mathrm{mg} / \mathrm{min}$ was terminated after $10 \mathrm{~min}$ due to cardiac dysfunction. The cumulative BAM15 dose before end of study was $37 \mathrm{mg}$.
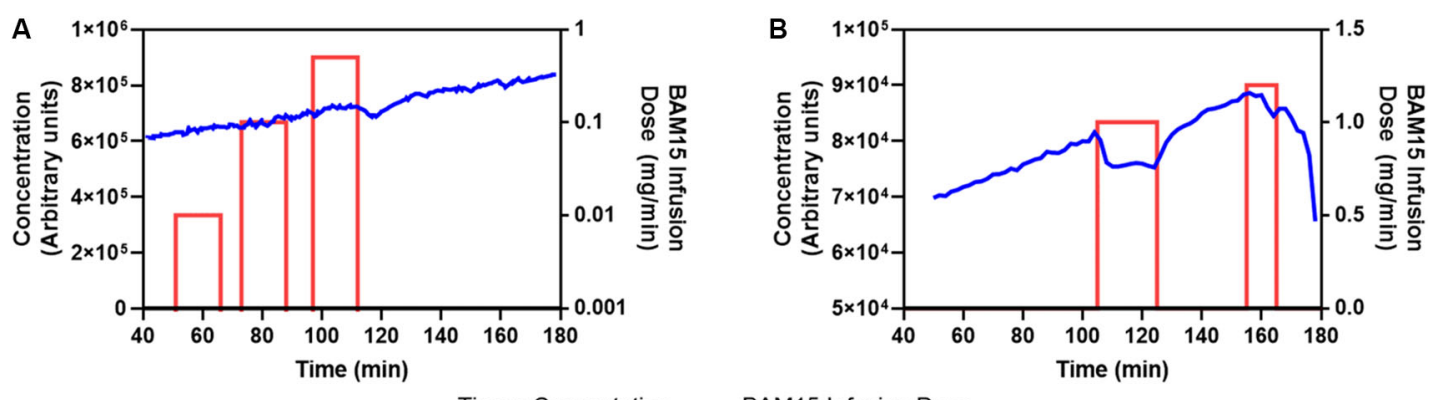

FIGURE 1 | First (A) and second (B) BAM15 dosing study. Blue line denotes PET average concentration measurements of ${ }^{18} \mathrm{~F}_{-} \mathrm{TPP}^{+}$in myocardium. The red bars indicate periods of BAM15 intracoronary infusion. The height of the bar is proportional to the BAM15 dose rate and is keyed to the dose rate scale on the right side of the graph. Cumulative BAM15 dose is obtained by multiplying the dose rate by the infusion time. A putative dose response is noted beginning at about 115 min in A; whereas, B suggests that the BAM15 infusion causes depolarization of mitochondria during the period 110-125 min. After the first BAM15 infusion was stopped, the ${ }^{18} \mathrm{~F}-\mathrm{TPP}+$ concentration resumed is original trajectory. 


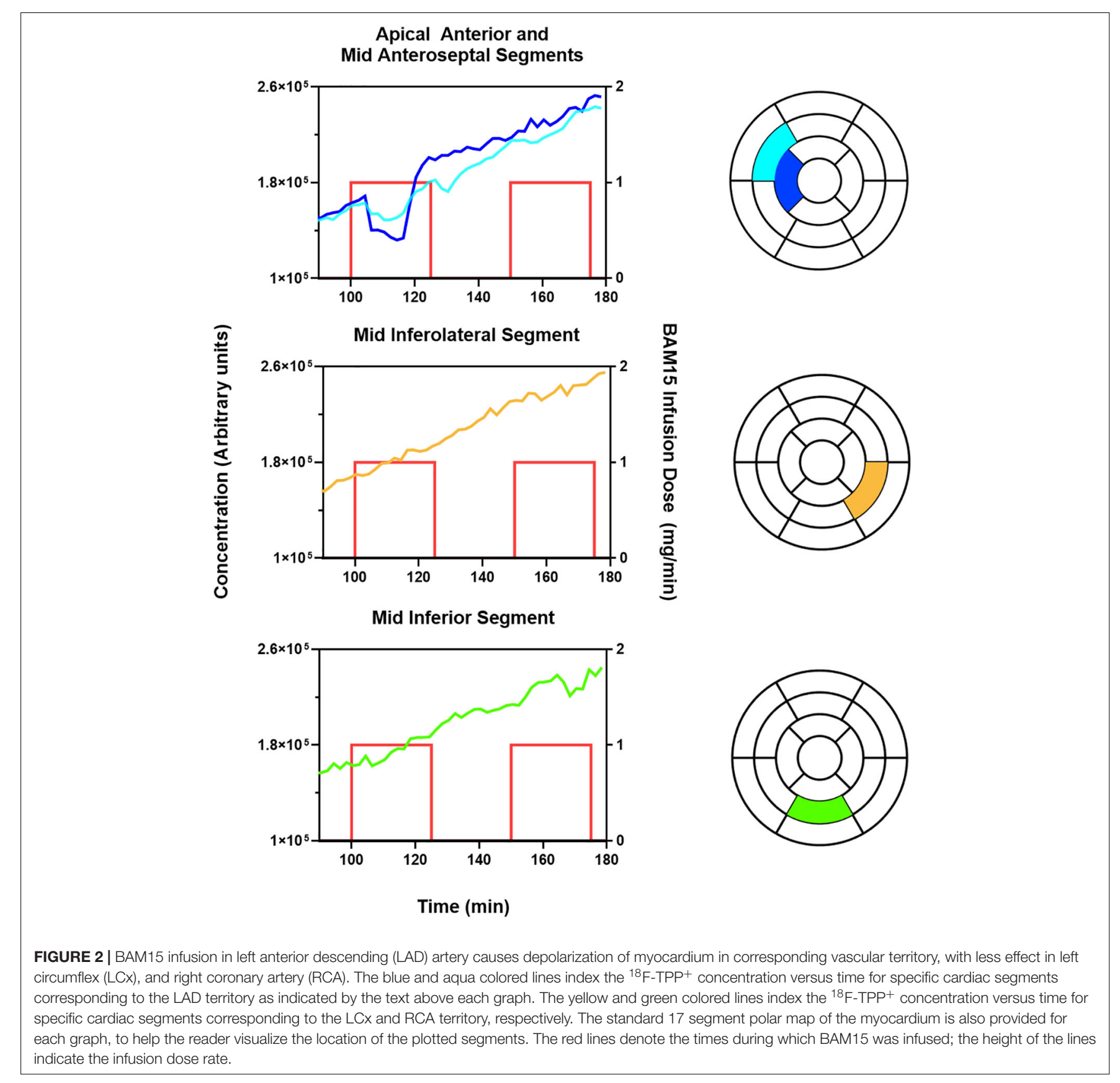

\section{Effect of BAM15}

Figure 2 demonstrates that BAM15 infusion into the mid LAD artery causes a decrease in the concentration of ${ }^{18} \mathrm{~F}_{-} \mathrm{TPP}^{+}$in the corresponding vascular territory. The top panel presents TACs for apical anterior and mid anteroseptal myocardium, segments 8 and 14 of the standard 17 segment polar model. Shortly after start of BAM15 infusion into the LAD, concentration of ${ }^{18} \mathrm{~F}-\mathrm{TPP}^{+}$ decreased, and remained depressed for about 10 min before beginning an upward trajectory. A second BAM15 infusion, begun 25 min later, demonstrated a much weaker response in these segments. Considering the whole myocardium, the response to BAM15 varied from segment to segment; greatest in apical segment 14 and least in segments 10 and 11 which are not parts of the LAD territory. These results are consistent with the placement of the catheter midway in the LAD artery and support the idea that it is possible to monitor, in real time, changes in ${ }^{18} \mathrm{~F}^{-} \mathrm{TPP}^{+}$concentration, as an indicator of mitochondrial membrane depolarization.

Figure 3 provides a more detailed quantitative analysis, comparing data obtained at secular equilibrium with and without BAM15. Parametric images of $\mathrm{V}_{\mathrm{T}}$ and $\Delta \Psi_{\mathrm{T}}$, are shown in the vertical long axis projection, allowing examination of effects in apex and septum. Color/intensity bars on the right side of Figure 3 provide a quantitative index of the parameter values. 


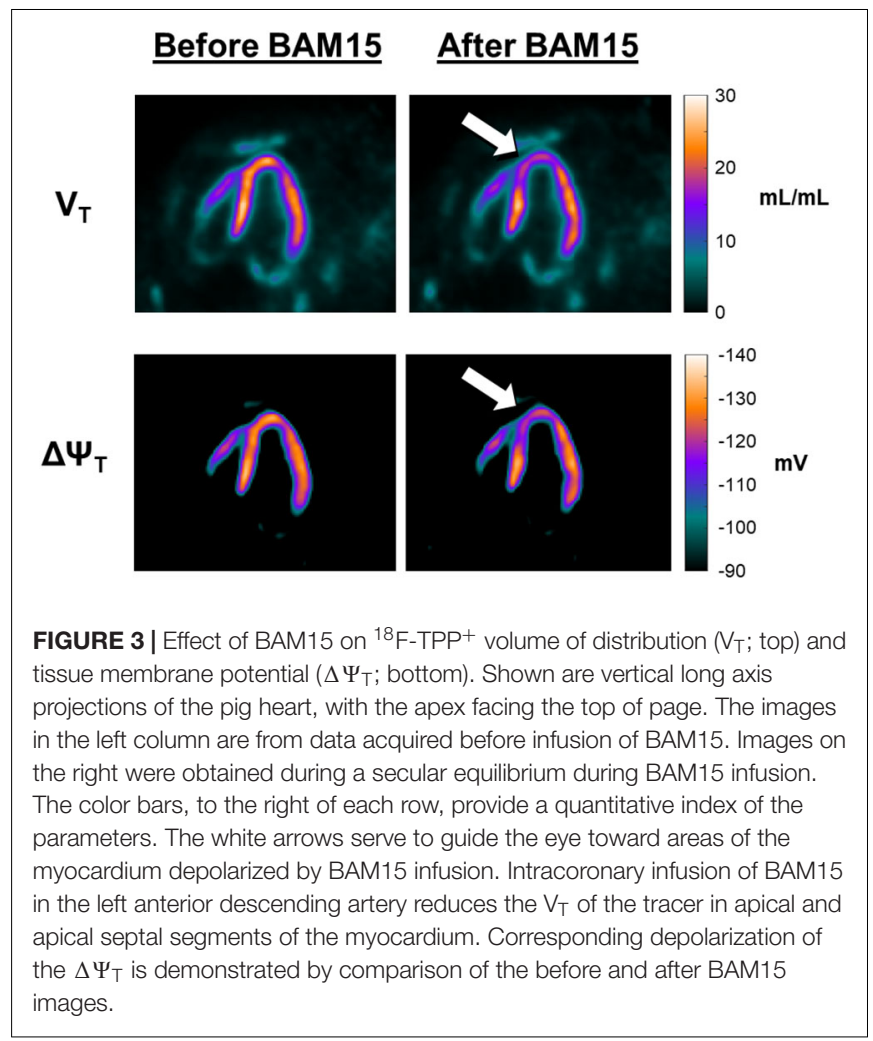

Before the infusion of BAM15 the parametric images of $\mathrm{V}_{\mathrm{T}}$ and $\Delta \Psi_{\mathrm{T}}$ are similar to those obtained in our earlier study (Alpert et al., 2018), with values of $\mathrm{V}_{\mathrm{T}}$ about $23 \mathrm{~mL} / \mathrm{mL}$ and $\Delta \Psi_{\mathrm{T}}$ near $-133 \mathrm{mV}$. Comparison with the "after BAM15" images shows that $\mathrm{V}_{\mathrm{T}}$ decreased to about $18 \mathrm{~mL} / \mathrm{mL}$ and $\Delta \Psi_{\mathrm{T}}$ fell to about $-119 \mathrm{mV}$. In other word, assuming that BAM15 did not affect the cellular membrane, there was about $10 \mathrm{mV}$ depolarization of mitochondrial membrane potential attributable to BAM15 uncoupling of the proton current.

\section{DISCUSSION}

The rationale for this study is to provide direct evidence that ${ }^{18} \mathrm{~F}$ $\mathrm{TPP}^{+}$can be used to assess acute depolarization of myocardial mitochondria. This work is an extension of our initial report (Alpert et al., 2018) which provided the first in vivo maps of total myocardial membrane potential in normal and chronically injured pig myocardia. In the case of chronic macroscopic tissue injury, there is probably a mixture of mitochondrial states, those with complete collapse of mitochondrial membrane potential and cell death, others with partial depolarization, and still others that are essentially normal. However, for applications such as early detection of cardiotoxicity, the ability to detect partial depolarization of myocardial mitochondria may be important for managing such injuries before depolarization leads to irreversible injury (McCluskey et al., 2019).

As noted above, BAM15 is a novel protonofore uncoupler, thought to be equipotent to carbonyl cyanide p-trifluoromethoxyphenylhydrazone (FCCP), that partially depolarizes the inner mitochondrial membrane but not the plasma membrane. The article by Kenwood et al. (Kenwood et al., 2014), mentions I.P. injection of BAM15 in mice but gives no dosing guidance for constant intracoronary infusion in large animals, nor does the literature discuss the total body distribution of BAM15, its kinetics or its metabolism. This study provides the first attempt to fill that gap, but it must be said that in this regard our work was expedient; our goal was simply to adjust the dose of BAM15 to produce an observable effect on the concentration history of ${ }^{18} \mathrm{~F}^{-\mathrm{TPP}^{+}}$in pig myocardium. In addition to the direct effects noted in heart muscle, it is likely that circulation of BAM15 causes similar effects in other tissues, such as liver and skeletal muscle. Investigating these effects was beyond the scope of this report.

Before starting this work, we did not have any prediction for the magnitude of depolarization that might result from infusion of BAM15. But Sack (2006) has reviewed the mitochondrial depolarization and the role of uncoupling proteins in ischemia tolerance, suggesting the maximal reduction of mitochondrial membrane potential with robust overexpression of the protonofore uncoupler UCP2 approaches $15 \mathrm{mV}$. Thus, it is interesting that in this study, despite direct coronary infusion of $1 \mathrm{mg} / \mathrm{min}$ over $25 \mathrm{~min}$, that we found modest depolarization of mitochondria in proximity of the catheter in the mid-LAD artery with maximum depolarization of about $-10 \mathrm{mV}$.

The basic results of this study, observation of reduction in the concentration of a highly lipophilic cation, ${ }^{18} \mathrm{~F}_{-} \mathrm{TPP}^{+}$in response to BAM15 infusion, are well supported by the data. However, there was considerable variation in the strength and location of response that cannot be fully evaluated with the small sample size of this study. Nevertheless, we can speculate that the variation in the effective catheter position in the LAD can explain much of the variation. On the other hand, there were cases in which the first BAM15 infusion provoked a strong depolarization whereas the second infusion did not produce an observable effect at the same location. We have no explanation for those findings. Finally, no control infusions were performed and DMSO and P80 could be involved in the observed changes of ${ }^{18} \mathrm{~F}_{-} \mathrm{TPP}^{+}$concentration. However, in the first dosing study, no change in ${ }^{18} \mathrm{~F}^{-} \mathrm{TPP}^{+}$concentrations was observed with the first two infusion of BAM15, which had same infusion rate to those producing changes $(1 \mathrm{~mL} / \mathrm{min})$, suggesting that the effects observed at higher doses of BAM15 were not related to the solvents DMSO and P80.

\section{CONCLUSION}

This pilot study demonstrates that it is possible to observe acute mitochondrial depolarization in vivo using PET imaging, thus confirming that our $\mathrm{TPP}^{+}$-PET methodology is sensitive to mitochondrial membrane potential. Intracoronary infusion of $1 \mathrm{mg} / \mathrm{min}$ of BAM15 over $25 \mathrm{~min}$ leads to measurable and transient depolarization of $\sim 10 \mathrm{mV}$. In vivo imaging of myocardial membrane potential with ${ }^{18} \mathrm{~F}_{-} \mathrm{TPP}^{+}$holds great potential in research and clinical applications. 


\section{DATA AVAILABILITY STATEMENT}

The datasets generated for this study are available on request to the corresponding author.

\section{ETHICS STATEMENT}

The animal study was reviewed and approved by the Institutional Animal Care and Use Committee of the Massachusetts General Hospital. Animals used in this study were housed and maintained under the supervision of the Massachusetts General Hospital (MGH) Institutional Animal Care and Use Committee (IACUC) and our study was conducted under a protocol approved by the MGH IACUC.

\section{AUTHOR CONTRIBUTIONS}

NA contributed to the conceptualization of the study, data analysis, and writing of the original draft. MP-G contributed to the conceptualization of the study, data acquisition and analysis, and writing of the original draft. SK, KR-T, and YP contributed

\section{REFERENCES}

Alpert, N. M., Guehl, N., Ptaszek, L., Pelletier-Galarneau, M., Ruskin, J., Mansour, M. C., et al. (2018). Quantitative in vivo mapping of myocardial mitochondrial membrane potential. PLoS One 13:e0190968. doi: 10.1371/ journal.pone.0190968

Aon, M. A., Cortassa, S., Marbã, N. E., and O’rourke, B. (2003). Synchronized whole cell oscillations in mitochondrial metabolism triggered by a local release of reactive oxygen species in cardiac myocytes. J. Biol. Chem. 278, 44735-44744. doi: 10.1074/jbc.m302673200

Barth, E., StãMmler, G., Speiser, B., and Schaper, J. (1992). Ultrastructural quantitation of mitochondria and myofilaments in cardiac muscle from 10 different animal species including man. J. Mol. Cell Cardiol. 24, 669-681. doi: 10.1016/0022-2828(92)93381-s

Buades, A., Coll, B., and Morel, J.-M. (2005). “A non-local algorithm for image denoising," in Proceedings of the 2005 IEEE Computer Society Conference on Computer Vision and Pattern Recognition (CVPR'05), (Piscataway, NJ: IEEE), 60-65.

Carson, R. E. (2000). PET physiological measurements using constant infusion. Nucl. Med. Biol. 27, 657-660. doi: 10.1016/s0969-8051(00)00138-4

Chen, L. B. (1988). Mitochondrial membrane potential in living cells. Ann. Rev. Cell Biol. 4, 155-181. doi: 10.1146/annurev.cb.04.110188.001103

Cui, H., Kong, Y., and Zhang, H. (2012). Oxidative stress, mitochondrial dysfunction, and aging. J. Signal Trans. 2012:646354.

De Felice, F. G., and Ferreira, S. T. (2014). Inflammation, defective insulin signaling, and mitochondrial dysfunction as common molecular denominators connecting type 2 diabetes to Alzheimer disease. Diabetes Metab. Res. Rev. 63, 2262-2272. doi: $10.2337 / \mathrm{db} 13-1954$

Dilsizian, V., Bacharach, S. L., Beanlands, R. S., Bergmann, S. R., Delbeke, D., Dorbala, S., et al. (2016). ASNC imaging guidelines/SNMMI procedure standard for positron emission tomography (PET) nuclear cardiology procedures. J. Nucl. Cardiol. 23, 1187-1226. doi: 10.1007/s12350-016-0522-3

Duchen, M. R. (2004). Roles of mitochondria in health and disease. Diabetes Metab. Res. Rev. 53, S96-S102.

Endres, C. J., and Carson, R. E. (1998). Assessment of dynamic neurotransmitter changes with bolus or infusion delivery of neuroreceptor ligands. J. Cereb. Blood Flow Metab. 18, 1196-1210. doi: 10.1097/00004647-199811000-00006

Fulda, S., Galluzzi, L., and Kroemer, G. (2010). Targeting mitochondria for cancer therapy. Nat. Rev. Drug Discov. 9:447. to the data acquisition and analysis as well as the review and editing of the manuscript. TS contributed to the data analysis. $\mathrm{MN}$ and GE contributed to the conceptualization of the study and the review and editing of the manuscript.

\section{FUNDING}

This work was funded by two grants from the United States National Institutes of Health: S10OD018035, P41-EB022544, and R01-HL137230. These grants were awarded as part of the standard peer review process for new grants. The study design and analysis are solely the work of the study authors, meaning that the funders had no role in study.

\section{ACKNOWLEDGMENTS}

Julia-Ann Scotton, Eric McDonald, and Marina MacDonaldSoccorso provided important technical assistance in this work. Jose Luis Guerrero, Brittan Morris performed the surgical preparation of the pigs. Pedro Brugarolas provided valuable advice.

Green, K., Brand, M. D., and Murphy, M. P. (2004). Prevention of mitochondrial oxidative damage as a therapeutic strategy in diabetes. Diabetes Metab. Res. Rev. 53, S110-S118.

Jastroch, M., Keipert, S., and Perocchi, F. (2014). From explosives to physiological combustion: next generation chemical uncouplers. Mol. Metab. 3:86. doi: 10. 1016/j.molmet.2014.01.003

Kadenbach, B., Ramzan, R., Moosdorf, R., and Vogt, S. (2011). The role of mitochondrial membrane potential in ischemic heart failure. Mitochondrion 11, 700-706. doi: 10.1016/j.mito.2011.06.001

Kamo, N., Muratsugu, M., Hongoh, R., and Kobatake, Y. (1979). Membrane potential of mitochondria measured with an electrode sensitive to tetraphenyl phosphonium and relationship between proton electrochemical potential and phosphorylation potential in steady state. J. Membr. Biol. 49, 105-121. doi: 10.1007/bf01868720

Kauppinen, R. (1983). Proton electrochemical potential of the inner mitochondrial membrane in isolated perfused rat hearts, as measured by exogenous probes. Biochim. Biophys. Acta Bioenerget. 725, 131-137. doi: 10.1016/0005-2728(83) 90232-3

Kenwood, B. M., Weaver, J. L., Bajwa, A., Poon, I. K., Byrne, F. L., Murrow, B. A., et al. (2014). Identification of a novel mitochondrial uncoupler that does not depolarize the plasma membrane. Mol. Metab. 3, 114-123. doi: 10.1016/j. molmet.2013.11.005

Klein, S., Staring, M., Murphy, K., Viergever, M. A., and Pluim, J. P. (2009). Elastix: a toolbox for intensity-based medical image registration. IEEE Trans. Med. Imaging 29, 196-205. doi: 10.1109/tmi.2009.2035616

Lee, H.-J., Im, D. J., Youn, J.-C., Chang, S., Suh, Y. J., Hong, Y. J., et al. (2016). Myocardial extracellular volume fraction with dual-energy equilibrium contrast-enhanced cardiac CT in nonischemic cardiomyopathy: a prospective comparison with cardiac MR imaging. Radiology 280, 49-57. doi: 10.1148/ radiol.2016151289

McCluskey, S., Haslop, A., Coello, C., Gunn, R., Tate, E., Southworth, R., et al. (2019). Imaging chemotherapy induced acute cardiotoxicity with $18 \mathrm{~F}$-labelled Lipophilic cations. J. Nuclear Med. 60, 1750-1756. doi: 10.2967/jnumed.119. 226787

Momcilovic, M., Jones, A., Bailey, S. T., Waldmann, C. M., Li, R., Lee, J. T., et al. (2019). In vivo imaging of mitochondrial membrane potential in non-small-cell lung cancer. Nature 575, 380-384.

Murphy, M. P. (2008). Targeting lipophilic cations to mitochondria. Biochim. Biophys. Acta Bioenerget. 1777, 1028-1031. doi: 10.1016/j.bbabio.2008.03.029 
Nernst, W. (1889). Die elektromotorische wirksamkeit der jonen. Zeitschrift Phys. Chem. 4, 129-181.

O'rourke, B. (2016). Metabolism: beyond the power of mitochondria. Nat. Rev. Cardiol. 13, 386-388. doi: 10.1038/nrcardio.2016.95

O'rourke, B., Cortassa, S., and Aon, M. A. (2005). Mitochondrial ion channels: gatekeepers of life and death. Physiology 20, 303-315. doi: 10.1152/physiol. 00020.2005

Pan, T., Einstein, S. A., Kappadath, S. C., Grogg, K. S., Lois Gomez, C., Alessio, A. M., et al. (2019). Performance evaluation of the 5-Ring GE Discovery MI $\mathrm{PET} / \mathrm{CT}$ system using the national electrical manufacturers association NU 2-2012 Standard. Med. Phys. 46, 3025-3033.

Perrier, D., and Mayersohn, M. (1982). Noncompartmental determination of the steady-state volume of distribution for any mode of administration. J. Pharm. Sci. 71, 372-373. doi: 10.1002/jps.2600710332

Pfeffer, G., and Chinnery, P. F. (2013). Diagnosis and treatment of mitochondrial myopathies. Ann. Med. 45, 4-16. doi: 10.3109/07853890.2011.605389

Rottenberg, H. (1979). [64] The measurement of membrane potential and $\Delta \mathrm{pH}$ in cells, organelles, and vesicles. Methods Enzymol. 55, 547-569. doi: 10.1016/ 0076-6879(79)55066-6

Rottenberg, H. (1984). Membrane potential and surface potential in mitochondria: uptake and binding of lipophilic cations. J. Membr. Biol. 81, 127-138. doi: 10.1007/bf01868977

Rutledge, C., and Dudley, S. (2013). Mitochondria and arrhythmias. Expert Rev. Cardiovasc. Ther. 11, 799-801. doi: 10.1586/14779072.2013.811969

Sack, M. N. (2006). Mitochondrial depolarization and the role of uncoupling proteins in ischemia tolerance. Cardiovasc. Res. 72, 210-219. doi: 10.1016/j. cardiores.2006.07.010

Suski, J., Lebiedzinska, M., Bonora, M., Pinton, P., Duszynski, J., and Wieckowski, M. R. (2018). Relation between mitochondrial membrane potential and ROS formation. Mitochond. Bioenerget. 810, 357-381. doi: 10.1007/978-1-49397831-1_22
To, T.-L., Cuadros, A. M., Shah, H., Hung, W. H., Li, Y., Kim, S. H., et al. (2019). A compendium of genetic modifiers of mitochondrial dysfunction reveals intra-organelle buffering. Cell 179, 1222-1238.

Treibel, T. A., Bandula, S., Fontana, M., White, S. K., Gilbertson, J. A., Herrey, A. S., et al. (2015). Extracellular volume quantification by dynamic equilibrium cardiac computed tomography in cardiac amyloidosis. J. Cardiovasc. Comput. Tomogr. 9, 585-592. doi: 10.1016/j.jcct.2015.07.001

Walters, A. M., Porter, G. A., and Brookes, P. S. (2012). Mitochondria as a drug target in ischemic heart disease and cardiomyopathy. Circ. Res. 111, 1222-1236. doi: $10.1161 /$ circresaha. 112.265660

Wan, B., Doumen, C., Duszynski, J., Salama, G., Vary, T. C., and Lanoue, K. F. (1993). Effects of cardiac work on electrical potential gradient across mitochondrial membrane in perfused rat hearts. Am. J. Physiol. 265, H453H453.

Widlansky, M. E., Wang, J., Shenouda, S. M., Hagen, T. M., Smith, A. R., Kizhakekuttu, T. J., et al. (2010). Altered mitochondrial membrane potential, mass, and morphology in the mononuclear cells of humans with type 2 diabetes. Transl. Res. 156, 15-25. doi: 10.1016/j.trsl.2010. 04.001

Conflict of Interest: The authors declare that the research was conducted in the absence of any commercial or financial relationships that could be construed as a potential conflict of interest.

Copyright (C) 2020 Alpert, Pelletier-Galarneau, Kim, Petibon, Sun, Ramos-Torres, Normandin and El Fakhri. This is an open-access article distributed under the terms of the Creative Commons Attribution License (CC BY). The use, distribution or reproduction in other forums is permitted, provided the original author(s) and the copyright owner(s) are credited and that the original publication in this journal is cited, in accordance with accepted academic practice. No use, distribution or reproduction is permitted which does not comply with these terms. 